\title{
Authors, geographies and the content of papers published in Geoenvironmental Disasters (2014-2018)
}

\author{
Adam Emmer ${ }^{1,2}$, Vít Vilímek ${ }^{2}$, Fawu Wang ${ }^{3,4^{*}}$ (D) and Zili Dai ${ }^{4}$
}

\begin{abstract}
Geoenvironmental Disasters - an open access journal of the International Consortium on Geo-disaster Reduction (ICGdR) - is being published since 2014. This contribution aims at characterising 115 papers published in the first five volumes of the journal (2014-2018) and outlining some future perspectives. It is shown what research topics (types of natural hazards and disasters) are a subject of published papers, what methods are employed to investigate them and what is the geographical focus. Further, it is shown who publishes research results in Geoenvironmental Disasters, international cooperation network and the impact of published papers. Based on these findings, we conclude that Geoenvironmental Disasters became established journal for disseminating results of research on diverse typers of natural disasters in various geographical environments accross the globe, and we opine that further advancement of the journal might be achieved by onward indexing efforts.
\end{abstract}

Keywords: Geoenvironmental disasters, Natural hazards, Bibliometrics, Scientometrics

\section{Introduction the five-year history of the journal}

The ICGdR is an international non-governmental and non-profit making scientific organization legally registered as a non-profit organization in 2013 in the Shimane Prefecture government according to the Japanese law. The ICGdR contributes to a safe and secured social and natural environment by promoting the reduction of disasters triggered by geological and geophysical phenomena on the earth.

Geoenvironmental Disasters is the official journal of the ICGdR. It is devoted to multi-disciplinary applied and fundamental research on various types of geoenvironmental hazards (e.g. typhoons, earthquakes, volcanic activity, landslides, floods, tsunamis and intensive erosion), and their impacts on the infrastructure, natural environment, and society. The journal publishes research papers, quick reports of recent geoenvironmental disasters and any efforts for geo-disaster reduction, review

\footnotetext{
* Correspondence: wangfw@riko.shimane-u.ac.jp

${ }^{3}$ Department of Earth Science, Shimane University, Matsue, Shimane

690-8504, Japan

${ }^{4}$ Center for Natural Disaster Research and Education, Shimane University,

Matsue, Shimane 690-8504, Japan

Full list of author information is available at the end of the article
}

papers, and technical reports of various geoenvironmental disaster-related case studies.

Geoenvironmental Disasters started publication by Springer as an open access journal in 2014. In the first 5 years, 115 papers have been published (see General characteristics section) and the journal acceptance rate was about $46.5 \%$. One best paper was selected by hte Editorial Board every year, and awarded in the International Symposium on Geo-disaster Reduction. The best papers in the first 4 years are listed in Table 1 (Wang et al. 2014; Tuladhar et al. 2015; Havenith et al. 2016; Casagli et al. 2017). Since 2019, the teaching material in the field school of UNESCO Chair on Geoenvironmental Disaster Reduction will be included in the special issue of Geoenvironmental Disasters, which can represent the up-to-date research results worldwide related to geoenvironmental disaster reduction. Recently, the journal has been accepted for coverage in Scopus, which marks an important milestone in the history of the journal. 
Table 1 Best Papers of the Geoenvironmental Disasters in the first 4 years

\begin{tabular}{lll}
\hline Title & Authors & Publication Year \\
\hline $\begin{array}{l}\text { Spaceborne, UAV and ground-based remote sensing tech } \\
\text { niques for landslide mapping, monitoring and early warning }\end{array}$ & $\begin{array}{l}\text { Nicola Casagli, William Frodella, Stefano Morelli, Veronica Tofani, } \\
\text { Andrea Ciampalini, Emanuele Intrieri, Federico Raspini, Guglielmo } \\
\text { Rossi, Luca Tanteri and Ping Lu }\end{array}$ \\
$\begin{array}{l}\text { A new classification of earthquake-induced landslide event } \\
\text { sizes based on seismotectonic, topographic, climatic and geo } \\
\text { logic factors }\end{array}$ & $\begin{array}{l}\text { Hans-Balder Havenith, Almaz Torgoev, Anika Braun, Romy Schlögel } \\
\text { and Mihai Micu }\end{array}$ \\
$\begin{array}{l}\text { Disaster risk reduction knowledge of local people in Nepal } \\
\text { Gangalal Tuladhar, Ryuichi Yatabe, Ranjan Kumar Dahal and Netra }\end{array}$ & 2015 \\
$\begin{array}{l}\text { Key factors influencing the mechanism of rapid and long } \\
\text { runout landslides triggered by the } 2008 \text { Wenchuan } \\
\text { earthquake, China }\end{array}$ & Fawu Wang, Ping Sun, Lynn Highland and Qiangong Cheng & 2014 \\
\hline
\end{tabular}

\section{Published papers (2014-2018)}

\section{General characteristics}

A total of 115 papers have been published in the first five volumes of Goenvironmental Disasters (2014-2018). Majority of these $(n=87 ; 75.7 \%)$ are classified as research articles, followed by methodological papers $(n=7 ; 6.1 \%)$ and editorials $(n=7 ; 6.1 \%)$. Short reports, reviews, databases, technical note and erratum were further published (see Table 2). While 7 papers were published in the first volume (2014), following volumes contain between 24 papers (2018) to 30 papers (2016). Each of 115 papers has been described by qualitative (e.g. research topic, methodological approach employed, geographical focus) and quantitative characteristics (e.g. times cited, number of references), which are further analysed in this paper.

\section{Research topics}

Eight different research topics were distinguished and used to describe each paper: (i) landslide studies (including all different types of slope movements and erosion); (ii) earthquake studies; (iii) flood studies (including coastal flooding and glacial lake outburst floods - GLOFs); (iv) tsunami studies; (v) drought studies; (vi) general climate change-related studies; (vii) general disaster risk reduction studies; and (viii) other studies. A total of 76 papers are assigned to

Table 2 Types of papers published in the first five volumes of Geoenvironmental Disasters

\begin{tabular}{llllllllll}
\hline Year & $\begin{array}{l}\text { Papers } \\
\text { published }\end{array}$ & \multicolumn{1}{l}{ Paper type } \\
\cline { 3 - 10 } & & RA & REW & METH & DATA & SR & EDIT & TN & ER \\
\hline 2018 & 24 & 19 & 2 & 1 & 1 & 0 & 1 & 0 & 0 \\
2017 & 28 & 23 & 0 & 0 & 0 & 2 & 3 & 0 & 0 \\
2016 & 30 & 21 & 1 & 3 & 0 & 2 & 1 & 1 & 1 \\
2015 & 26 & 20 & 0 & 3 & 1 & 1 & 1 & 0 & 0 \\
2014 & 7 & 4 & 1 & 0 & 0 & 1 & 1 & 0 & 0 \\
total & 115 & 87 & 4 & 7 & 2 & 6 & 7 & 1 & 1 \\
\hline
\end{tabular}

$R A$ research article, $R E W$ review, $M E T H$ methodology, DATA database, SR short report, EDIT editorial (including acknowledgement to reviewers), $T N$ technical note, $E R$ erratum one of these categories, while 33 studies are assigned to two or more categories (i.e., multi-hazard studies; e.g. studies of earthquake-induced landslides) and 6 papers are not assigned to any of eight categories (editorials). Landslides studies dominate among the published papers $(n=60 ; 52.2 \%)$, followed by earthquake studies $(n=21 ; 18.3 \%)$, flood studies $(n=16 ; 13.9 \%)$, general climate change-related studies $(n=10 ; 8.7 \%)$ and general disaster risk reduction studies $(n=8$; 7.0\%). Other research topics are represented marginally.

Wordcloud analysis of the most frequently used words among the titles of published papers has been employed, using wordclouds.com online tool. This analysis confirmed the dominance of research on landslides (48 hits; see Fig. 1). As for other specific hazard types, earthquake (7 hits), flood (6 hits), rainfall (5 hits) and tsunami (3 hits) are represented. Hazard (11 hits), risk (11 hits), susceptibility (9 hits), mitigation (4 hits) and vulnerability, disaster, response and damage (3 hits each) are among the general disaster risk management terms represented. As for the geographical terms, China (11 hits), Nepal (7 hits), India (6 hits), Indonesia (5 hits), Japan (5 hits), Ethiopia, Nigeria and Peru (3 hits each) are represented (see also 2.4).

\section{Employed methodological approaches}

Six types of general methodological approaches are distinguished and one or more methodological types are assignedto each paper published. We distinguish between: (i) field data-based studies; (ii) remotely sensed images-based studies; (iii) laboratory experiments-based studies; (iv) modelling-based studies; (v) participatory method-based studies (interviews, public surveys); (vi) reviews. It is shown that 56 papers $(48.7 \%)$ employ one of the methodological approaches defined above (i.e., single-approach papers), while 50 papers $(43.5 \%)$ use a combination of two or more methodological approaches defined above (i.e., multi-approach papers); remaining 9 papers do not employ any methodological approach (editorials, erratum). 


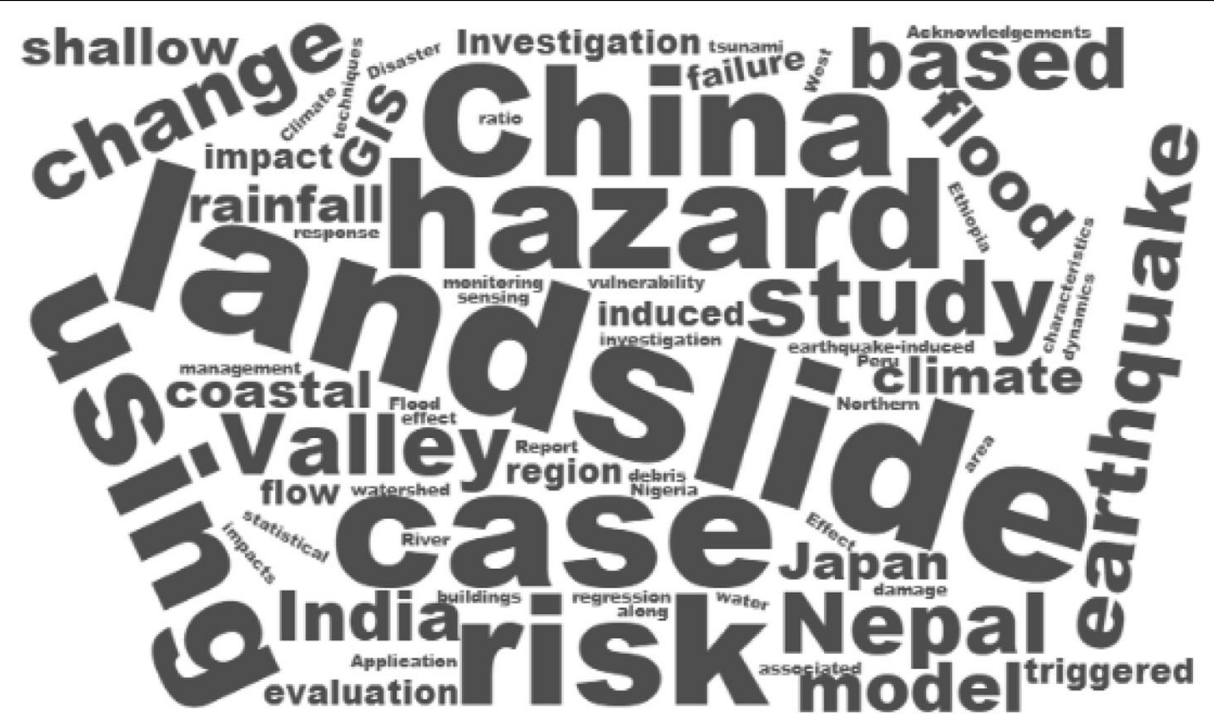

Fig. 1 Word cloud representation of the most frequently used words in the titles of 115 analysed papers. Only words occuring three times or more are displayed $(n=80)$. The size of the font indicates the frequency of occurrence (3-48 hits)

Among those single-approach papers, modelling-based studies dominate $(n=22)$, followed by field data-based studies $(n=11)$ and participatory method-based studies $(n=8)$. Multi-approach papers typically employ a combination of remotely sensed data and modelling $(n=13)$ and a combination of field data and laboratory experiments $(n=11)$. Considering both single-approach papers and multi-approach papers, majority are employing modelling $(n=58)$, field data $(n=35)$, remotely sensed data $(n=28)$, laboratory experiments $(n=16)$ and participatory methods $(n=14)$.

\section{Geographical focus}

Geographical focus is assigned to 101 out of 115 published papers (i.e., 87.8\%), spanning all continents excluding Antarctica. A total of 59 studies $(58.4 \%$ of studies with geographical focus) are focused on Asia, 15 studies to Africa (14.9\%), 15 studies to Europe (14.9\%), 7 studies on North America (6.9\%), 4 studies on South America (4.0\%) and 1 study on Australia (1.0\%). One study has global coverage and two studies focus on more than one country. A total of 28 different countries are covered in papers published in Geoenvironmental Disasters and the highest attention is attracted by China $(n=$ $18 ; 17.8 \%)$, followed by India, Nepal and Italy $(n=9$; 8.9\% each). Emmer (2018) analysed geographical focus of more than half milion WOS-indexed studies on different types of natural hazards, identifying hotspots of research on natural hazards as well as 'under-researched'regions (see Fig. 2a). Papers published in Geoenvironmental Disasters reflect global trends and hotspots of research on natural hazards (see Fig. $2 \mathrm{~b}$ for comparison).

\section{Authors and countries}

Authors affiliated with institutions in 40 different countries published their research in Geoenvironmental Disasters. Out of these, the authors affiliated with the institutions located in China and Japan contributed to 28 papers each $(24.3 \%)$, followed by Italy and Nepal $(n=$ $10 ; 8.7 \%)$, USA $(n=9 ; 7.8 \%)$, India $(n=8 ; 6.9 \%)$, Canada $(n=7 ; 6.1 \%)$, Indonesia and France $(n=6 ; 5.2 \%$; see Fig. 3a). This differentiates Geoenvironmental Disasters from the general trend of research on natural hazards, which is globally dominated by the authors affiliated with institutions located in the USA (see Emmer 2018) and may be explained by the increased representation of Chinese and Japanese institutions in the ICGdR.

Only 5 research articles, 4 editorials and 2 review papers (i.e., 9.6\% of all) have been written by individuals, while remaining 104 papers were written by teams, confirming previously published hypothesis about dominant role of teams in producing knowledge (Wuchty et al. 2007). Out of the 104 papers written by teams, 45 papers have been written by international teams (i.e., $39.1 \%$ of all), while remaining papers were written by individuals or mononational teams. A cooperation network between individual countries is visualised in Fig. 3b. Three main clusters of more intense cooperation are observed: (i) Japan-ChinaNepal-Indonesia; (ii) Belgium-Germany-Kyrgyzstan; (iii) Austria-Czech Republic-Norway-Netherlands. These clusters, however, reflect relatively low number of cooperation ties and are, thus, sensitive to change.

\section{Views and citations}

As of in May 2019, papers published in Geoenvironmental Disasters were accessed about 280,000 times (i.e., an 


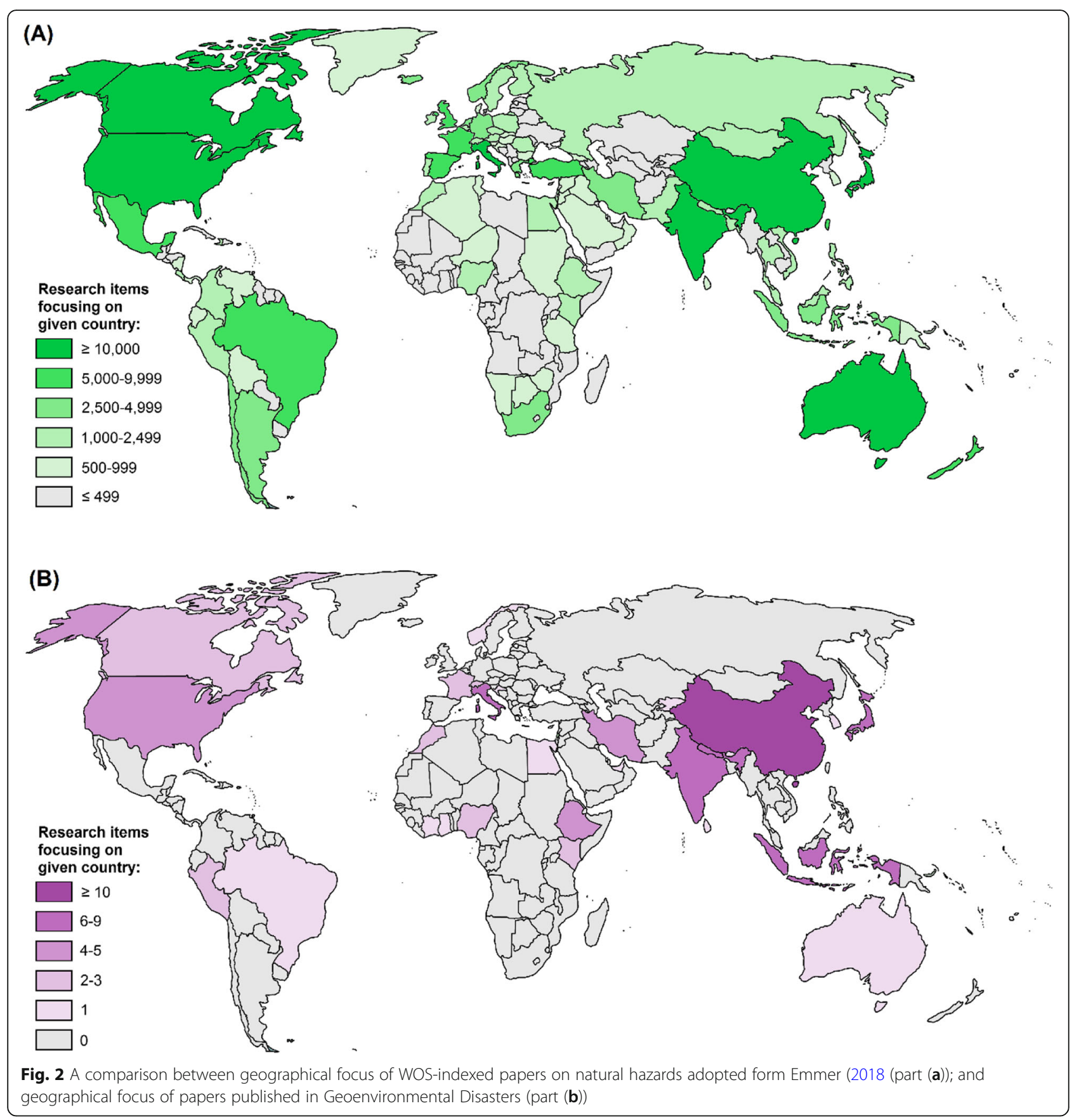

average of more than 2430 views per paper), ranging from 371 to 16,417 views per paper (the most accessed paper of Wang et al. 2014; see Fig. 4a). Considering publishing years of individual papers, view per year vary from 180 to 3680 views per year. Published papers obtained a total of $417 \mathrm{ci}-$ tations (based on Citations.Springer.com tool), i.e., an average of 3.63 citations per paper. The two most cited papers obtained 27 citations each (Anbalagan et al. 2015; Casagli et al. 2017). The relationship between views and citations is, however, weak. A total of 71 papers (i.e., $61.7 \%$ of all) obtained at least 1 citation; the majority of not cited papers are, however, those published in last two volumes (20172018; see Fig. 4b).

Considering different research topics, it is revealed that landslide studies were cited 4.94 times on average, while papers on earthquakes 2.81 times on average and papers on flood 2.61 times on average. It is also shown that multi-hazard papers are slightly more cited ( $4.00 \mathrm{ci}$ tations per paper on average) compared to single-hazard papers (3.46 citations per paper). Considering different types of papers, research articles obtained 3.65 citations on avergae, while methodological papers 6.42 citations 


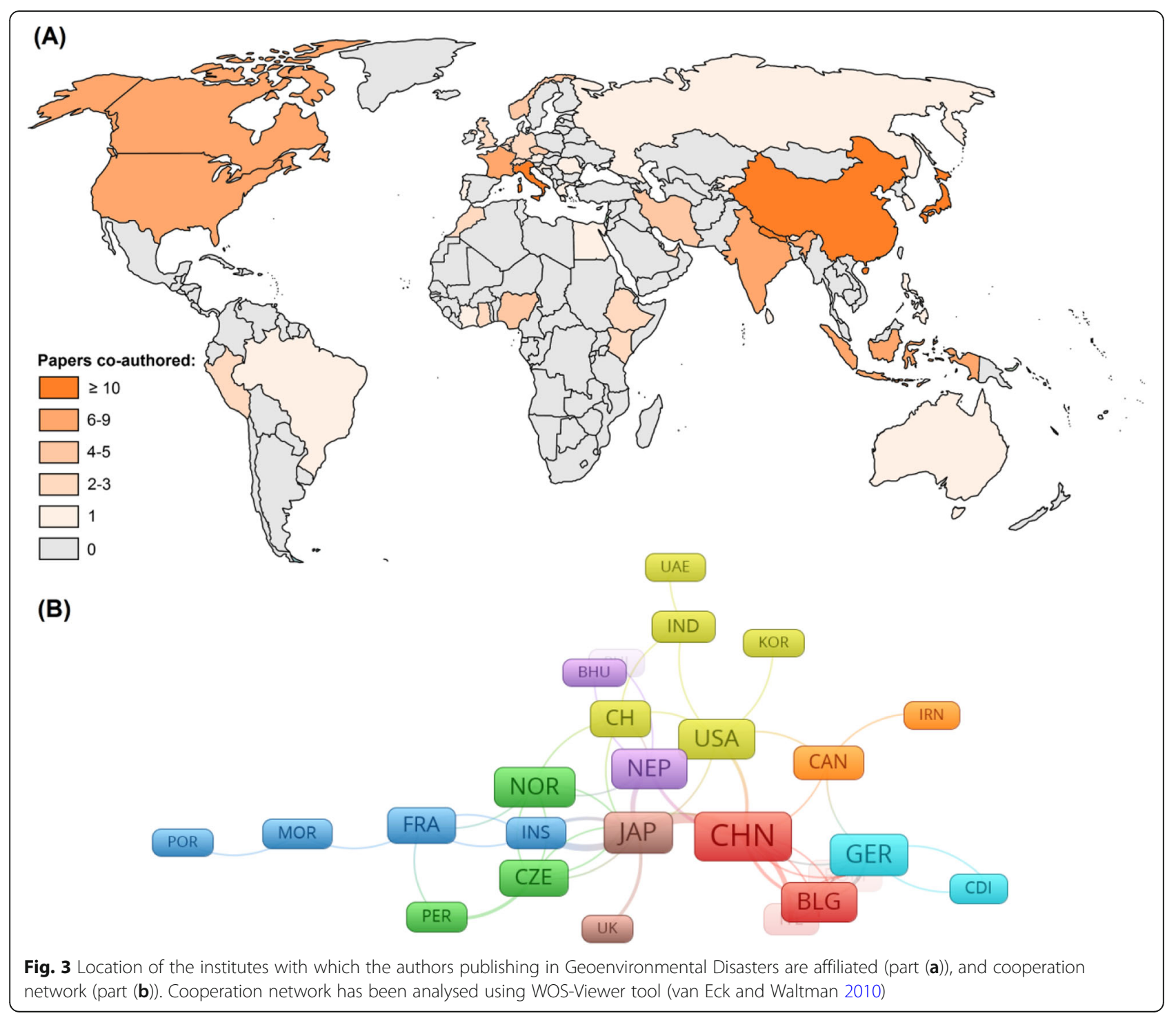

on average and review papers 7.00 citations on average (low number of review papers, however, need to be taken into consideration). Multi-approach papers have similar citations (3.56 citations per paper) compared to single-approach papers (3.68 citations per paper).

\section{Future perspectives}

\section{SWOT analysis}

The journal is rather strong in terms of complexity and methods used for the research. This fact could be revealed from the first few years of publishing, nevertheless more detailed evaluation could be done after another 5 years. The other positive factor is that in rather short time an international journal has been created with wide scope of authors as well as research field areas. To support the journal quality, we need also to identify weaknesses. The analysis also revealed that Geoenvironmental Disasters have rather low share of papers outside the ICGdR community. For the early stage of the journal life it is obvious that mainly the ICGdR members are willing to contribute, but this trend should be changed and we have to attract the whole "hazard community". For instance special thematic issues could address the appropriate scientific community and bring the journal into the focal point of their interest. When the journal will build up a regular range of readers the journal will start to be attractive for papers of the highest research quality.

\section{Suggestions and recommendations}

Since we entered the SCOPUS database in 2019, the journal will start to be more attractive for several other research teams and international activity of core members of ICGdR will help to promote the journal worldwide. The next quality milestone is to enter the Web of Science database and further aim at enhancing the values of indexes calculated by SCOPUS (SJR, SNIP and Cite Score) - 

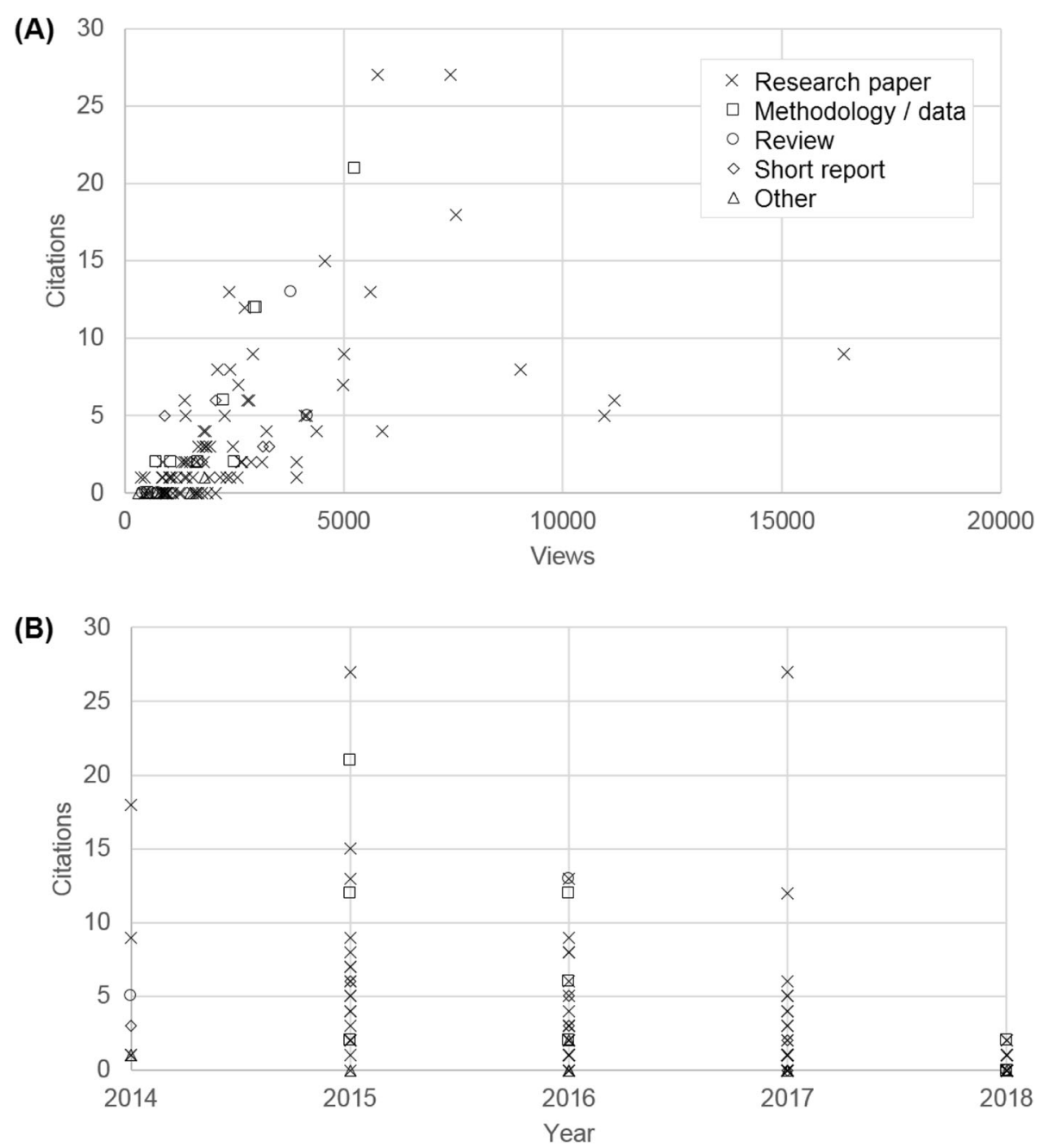

Fig. 4 The relationship between views and citations for different types of papers published (Part (a)) and citations obtained by years (Part (b))

to strengthen the position of the International Consortium on Geo-disaster Reduction in the frame of the international community dealing with natural hazards and risks. The journal Geoenvironmental Disasters is considered as one of the columns for ICGdR (research, publishing, conferences) which work in synergy for disaster risk reduction.

\section{Acknowledgements}

This work was supported by Inter-Excellence programme of the Ministry of Education, Youth and Sports of the Czech Republic, INTER-VECTOR project LTV19010, and by the Ministry of Education, Youth and Sports of the Czech Republic within the National Sustainability Programme I (NPU I), grant number LO1415.

\section{Authors' contributions}

Emmer and Vilemek wrote the first draft. Wang revised the first draft. All authors read and approved the final manuscript.

\section{Competing interests}

The authors declare that they have no competing interests.

\section{Author details}

${ }^{1}$ The Czech Academy of Sciences, Global Change Research Institute, 60300 Brno, Czech Republic. ${ }^{2}$ Faculty of Science, Charles University, 12843 Prague, Czech Republic. ${ }^{3}$ Department of Earth Science, Shimane University, Matsue, Shimane 690-8504, Japan. ${ }^{4}$ Center for Natural Disaster Research and Education, Shimane University, Matsue, Shimane 690-8504, Japan.

Received: 13 June 2019 Accepted: 11 November 2019

Published online: 21 November 2019

\section{References}

Anbalagan R, Kumar R, Lakshmanan K, Parida S, Neethu S (2015) Landslide hazard zonation mapping using frequency ratio and fuzzy logic approach, a case study of Lachung Valley, Sikkim. Geoenvironmental Disasters 2:6

Casagli N, Frodella W, Morelli S, Tofani V, Ciampalini A, Intrieri E, Raspini F, Rossi G, Tanteri L, Lu P (2017) Spaceborne, UAV and ground-based remote sensing techniques for landslide mapping, monitoring and early warning. Geoenvironmental Disasters 4:9

Emmer A (2018) Geographies and Scientometrics of research on natural hazards. Geosciences 8(10):382

Havenith HB, Torgoev A, Braun A, Schlögel R, Micu M (2016) A new classification of earthquake-induced landslide event sizes based on seismotectonic, topographic, climatic and geologic factors. Geoenvironmental Disasters 3:6

Tuladhar G, Yatabe R, Dahal RK, Bhandary NP (2015) Disaster risk reduction knowledge of local people in Nepal. Geoenvironmental Disasters 2:5 
van Eck NJ, Waltman L (2010) Software survey: VOSviewer, a computer program for bibliometric mapping. Scientometrics 84:523-538

Wang F, Sun P, Highland L, Cheng Q (2014) Key factors influencing the mechanism of rapid and long runout landslides triggered by the 2008 Wenchuan earthquake, China. Geoenvironmental Disasters 1:7

Wuchty S, Jones BF, Uzzi B (2007) The increasing dominance of teams in production of knowledge. Science 316:1036-1039

\section{Publisher's Note}

Springer Nature remains neutral with regard to jurisdictional claims in published maps and institutional affiliations.

\section{Submit your manuscript to a SpringerOpen ${ }^{\odot}$ journal and benefit from:}

- Convenient online submission

- Rigorous peer review

- Open access: articles freely available online

- High visibility within the field

- Retaining the copyright to your article

Submit your next manuscript at $\boldsymbol{\nabla}$ springeropen.com 